\title{
INTERVENÇÃO DO MÉTODO PILATES EM IDOSOS NO BRASIL: UMA REVISÃO SISTEMÁTICA
}

\author{
PILATES METHOD INTERVENTION IN ELDERLY ON BRAZIL \\ Thaís Mota Figueiredo ${ }^{\mathrm{a}^{*}}$, Laila Cristina Moreira Damázio ${ }^{\mathrm{b}^{*}}$ \\ thaismotafigueiredo@hotmail.comª , lailacmdamazio@gmail.com ${ }^{\mathrm{b}}$ \\ Universidade Presidente Antônio Carlos (UNIPAC) - Barbacena-MG, Brasil ${ }^{\star}$
}

Data do recebimento do artigo: $01 / 03 / 2018$

Data do aceite: $02 / 07 / 2018$

\section{RESUMO}

Introdução: $\mathrm{O}$ método Pilates tem sido considerado um sistema de exercício que visa à melhoria da flexibilidade, resistência física, força, equilíbrio e coordenação motora. Desta forma, muitos idosos têm procurado o método em busca dessa melhoria ou manutenção da saúde. O método Pilates encontra-se bastante difundido no Brasil, sendo uma das técnicas utilizadas pelos fisioterapeutas no tratamento de diversas disfunções na população idosa. Objetivo: O objetivo deste estudo foi analisar os aspectos relacionados ao uso do método pilates em idosos no Brasil. Métodos: A revisão sistemática foi feita nas bases de dados Scielo, Lilacs/Bireme, Medline/Bireme, Index Psicologia/Bireme e Pedro a partir dos descritores Pilates method, elderly, aging, physiotherapy. Os critérios de inclusão foram artigos originais de origem brasileira com populações adultas ( $\geq 60$ anos), sem restrição ao ano de publicação e idiomas português, inglês ou espanhol, textos completos disponíveis. Resultados: A presente revisão sistematizada demonstrou que o método Pilates pode ser indicado para a população idosa promovendo muitos benefícios à saúde. A maioria dos estudos brasileiros mencionou que o tempo da sessão deverá ser de sessenta minutos e que o método pilates seja aplicado duas vezes por semana. Conclusões: Este estudo demonstra que o Pilates pode ser um método eficaz para o fisioterapeuta na prevenção e tratamento das desordens geriátricas, apresentando vários benefícios e alguns cuidados ao realizá-lo; como, os exercícios devem ocorrer de forma progressiva, sempre respeitando os princípios do método e a evolução dos praticantes.

Palavras-chave: Método pilates; idosos; envelhecimento; fisioterapia.

\section{ABSTRACT}

Introduction: The Pilates method has been considered a system of exercise that aims the improvement of flexibility, physical resistance, strength, stability and motor coordination. In this way, elderly people have sought the method in quest for improvement or maintenance of health. The Pilates method is quite widespread in Brazil, being is one of the methods used to by physiotherapists in the treatment of many dysfunctions of elderly population. Objective: The objective of this study was to analyze the related aspects the use of the Pilates method in elderly people on Brazil. Methods: The systematic review was done in the databases of Scielo, Lilacs/Bireme, Medline/ Bireme, Index Psychology/ Bireme and Pedro stem from descriptors: Pilates method, elderly, aging, physiotherapy. The inclusion criteria were original articles of brazilian source with adult populations ( $\geq 60$ years), without restriction at the year of publication and Portuguese, English or Spanish languages, available complete texts. Results: The present systematized review demonstrated that Pilates method can be indicated for elderly population promoting many benefits to health. Most of the brazilian studies mentioned that time of the session will be of sixty minutes and that Pilates method be applied twice a week. Conclusions: This study demonstrates 
that the Pilates can be effective method the physiotherapist in the prevention and treatment of geriatric disorders, presenting several benefits and some cares when to perform it; how, the exercises should occur in a progressive form, always respecting the principles of the method and the evolution of practitioners.

Keywords: Pilates method; elderly; aging; physiotherapy. 


\section{Introdução}

De acordo com a Organização Mundial da Saú$\mathrm{de}^{1}$, a proporção de pessoas com mais de 60 anos está crescendo mais rápido do que qualquer outro grupo etário na maioria dos países, isso ocorre devido uma expectativa de vida mais longa e devido o declínio nas taxas de fertilidade.

No Brasil, nos últimos 20 anos esta população dobrou, ocupando, em 2015, a sétima colocação mundial em número de idosos. Em 2025 a expectativa é que haverá cerca de 32 milhões de idosos, o que representará $14,0 \%$ da população brasileira. É necessário que o aumento da expectativa de vida seja acompanhado de melhorias das condições de vida. Ampliar a quantidade de anos vividos é pouco, os idosos precisam desfrutar de uma vida ativa e saudável ${ }^{2}$.

Atualmente, compreende-se por envelhecimento o fenômeno biopsicossocial que atinge o homem e sua existência na sociedade, no qual manifesta em todos os domínios da vida ${ }^{3}$. O processo de envelhecimento está associado ao declínio nos sistemas neuromuscular e cardiovascular, o número de células que compõem o corpo diminui, a atividade de cada uma das células se deteriora, resultando na síndrome de fragilidade. Assim, a adaptabilidade física é gradualmente perdida, resultando na diminuição da capacidade de realizar atividades diárias, o que coloca os indivíduos em risco de incapacidade, perda de independência e hospitalização ${ }^{4}$.

Além dos fatores biológicos, a redução do desempenho funcional do idoso pode estar associada ao sedentarismo, ao tabagismo e a hábitos alimentares inadequados ${ }^{5}$; podendo influenciar e trazer sérias consequências em relação à qualidade de vida, como hipertensão, colesterol alto, dislipidemia, desnutrição, obesidade, entre outros² ${ }^{2}$.

Nessa perspectiva, a prática de atividade física regular tem sido amplamente descrita na melhora da qualidade de vida durante a senescência ${ }^{6}$. Diferentes programas de atividades físicas e exercícios estão sendo criados para os idosos; porém, o método pilates tem sido amplamente popularizado ${ }^{7}$.

$\mathrm{O}$ método Pilates tem sido considerado um sistema de exercício que visa à melhoria da flexibilidade, resistência física, força, equilíbrio e coordenação motora. Desta forma, muitos idosos têm procurado o método em busca dessa melhoria ou manutenção da saúde ${ }^{8}$.

Idealizado pelo alemão Joseph Hubertus Pilates (1880-1967) durante a Primeira Guerra Mundial, o qual apresentava grande fraqueza muscular, devido a várias enfermidades. Isto o incentivou a estudar e buscar força muscular em exercícios diferentes dos conhecidos em sua época9 ${ }^{9}$. Mas somente na década de 1980 passou a ser reconhecido internacionalmente, e nos anos 1990 ganhou popularidade, principalmente no campo da reabilitação ${ }^{10}$. Baseando-se em princípios da cultura oriental, como ioga, artes marciais e meditação, o Pilates se caracteriza pela tentativa do controle dos músculos envolvidos nos movimentos da forma mais consciente possível. O método se baseia no conceito da contrologia, em que todos os movimentos do corpo devem ser totalmente conscientes, entendendo seus princípios de equilíbrio e gravidade nos diferentes momentos ${ }^{11}$.

Os princípios do método são: respiração, centralização, concentração, controle, precisão e fluidez interagindo com a mente e o corpo ${ }^{12}$. O método é constituído de exercícios que envolvem contrações isotônicas (concêntricas e excêntricas) e isométricas, com ênfase no que seu criador denominou de power house (ou centro de força), que é composto pelos músculos abdominais, paravertebrais lombares e glúteos, responsáveis pela estabilização estática e dinâmica do corpo. Durante a execução dos exercícios, a expiração deve ser associada com a contração do diafragma, do transverso abdominal, dos multífidos e dos músculos do assoalho pélvi$\mathrm{Co}^{13}$. Os exercícios podem ser realizados em solo ou em aparelhos specíficos com a utilização de molas que geram resistência de carga ou auxílio para musculatura envolvida ${ }^{14}$.

O método Pilates encontra-se bastante difundido no Brasil, sendo uma das técnicas utilizadas pelos fisioterapeutas no tratamento de diversas disfunções na população idosa, tornando imprescindível que se conheça suas aplicações, forma de utilização, contraindicações, entre outras características. O método promove prevenção e tratamento das desordens geriátricas. Sendo assim, o objetivo geral deste estudo foi analisar os aspectos relacionados ao uso do método Pilates em idosos no Brasil. 


\section{Métodos}

Este é um estudo de revisão sistemática, que de acordo com Sampaio e Mancini ${ }^{15}$ é uma forma de investigação científica que tem por objetivo buscar, conduzir, avaliar e integrar uma síntese dos resultados de vários estudos primários sobre o tema proposto neste estudo.

A busca eletrônica foi conduzida nas seguintes bases de dados: Scielo, Lilacs/Bireme, Medline/ Bireme, Index Psicologia/Bireme e Pedro. Os Descritores em Ciência da Saúde (DeCS) utilizados foram: pilates method, elderly, aging, physiotherapy, no idioma inglês e seus correspondentes em português. Os descritores foram usados com as seguintes combinações: pilates method and elderly, pilates method and aging, pilates method and physiotherapy.

Os critérios de inclusão foram artigos originais de origem brasileira com populações adultas $(\geq 60$ anos), sem restrição ao ano de publicação e idiomas português, inglês ou espanhol, textos completos disponíveis. Os critérios de exclusão foram artigos de revisão, teses e dissertações.

\section{Resultados}

Após a busca nas diferentes bases de dados, foram identificados 156 artigos, sendo que, 117 foram descartados em função do tema não relacionar aos objetivos da presente revisão. Desses, 02 foram excluídos por serem duplicados, 19 foram excluídos após a leitura dos resumos. Dessa forma, foram selecionados 18 artigos que preencheram os critérios de inclusão e compuseram a revisão sistemática, conforme mostra o organograma da figura 1.

Em relação aos estados brasileiros em que os estudos foram feitos, identificaram-se um estudo na Bahia ${ }^{4}$, um em Minas Gerais ${ }^{11}$, dois no Pará ${ }^{5,16}$, três no Paraná ${ }^{2,13,17}$, um em Pernambuco ${ }^{18}$, dois no Piaui ${ }^{19,20}$, um no Rio de Janeiro ${ }^{10}$, dois no Rio Grande do Sul ${ }^{3,7}$, dois em Santa Catarina ${ }^{21,22}$ e três estudos em São Paulo 6,23,24.

Na tabela 1 está demonstrada as principais características dos artigos que compõe o presente estudo de revisão sistemática. Dentre esses artigos, encontraram-se 04 estudos de ensaios controlados randomizados ${ }^{6,7,17,19}, 01$ estudo quantitativo com delineamento transversal ${ }^{10}, 01 \mathrm{com}$ delineamento experimental de caso único ${ }^{21}, 01$ descritivo de corte transversal ${ }^{3}, 01$ experimental controlado $^{22}, 01 \mathrm{de}$ ensaio clínico, longitudinal e prospectivo ${ }^{11}, 01 \mathrm{de}$ projeto de extensão universitária ${ }^{18}, 01$ randomizado e longitudinal ${ }^{23}, 01$ descritivo quantitativo e comparativo ${ }^{20}, 01$ de ensaio clínico randomizado ${ }^{4}$, 01 quase-experimental ${ }^{2}, 02$ estudos quantitativos de caráteres aleatórios ${ }^{5,16}, 01$ estudo qualitativo de caráter exploratório ${ }^{24}$ e 01 pré-experimental ${ }^{13}$. As publicações compreenderam o período de $2002^{18}$ a $2018^{7}$, sendo que, as amostras dos estudos variaram de $07^{11}$ a $116^{3}$ idosos. A idade mínima relatada foi de 60 anos. Um estudo apresentou amostra entre 52 a 84 anos $^{24}$ e outro apresentou amostra entre 58 a 60 anos $^{13}$. Estes estudos foram incluídos, pois havia participantes idosos que praticaram $o$ método pilates. Houve 06 estudos com amostras compostas por ambos os sexos ${ }^{3,4,10,21,22,24}$ e 12 por mulheres. O período de intervenção variou de 04 semanas $^{19,20}$ a 11 meses $^{18}$.

De acordo com os parâmetros utilizados nos exercícios, a frequência variou entre 2 a 3 vezes por semana, com duração de 40 a 60 minutos. Os principais efeitos observados com o método pilates foram: melhora na percepção de saúde ${ }^{7}$; qualidade de sono ${ }^{7}$; sociabilidade ${ }^{10}$; prazer $^{10}$; melhora das condições emocionais ${ }^{10}$; prevenção à depressão $0^{3}$; melhora da flexibilidade do quadril e da cintura escapular ${ }^{22}$; da pressão expiratória máxima (PEmáx $)^{11}$; do equilíbrio estático e dinâmico ${ }^{13,16,19,23}$; da funcionalidade ${ }^{5,17}$ e da força muscular dos membros superiores ${ }^{17,18}$; da musculatura abdominal ${ }^{18}$; estabilizadores lombares ${ }^{20}$; glúteos ${ }^{18}$; adutores e abdutores ${ }^{18}$; redução da dor ${ }^{6,18}$; da diminuição da hipercifose torácica ${ }^{23}$; redução dos níveis séricos de proteína C reativa de alta sensibilidade (PCR-hs) ${ }^{4}$; redução das medidas antropométricas ${ }^{4}$; melhora na execução das atividades de vida diárias ${ }^{18}$; prevenção de quedas e risco de lesões ${ }^{18}$; melhora da autonomia funcional ${ }^{5,21}$ e da qualidade de vida ${ }^{6,21}$.

\section{Discussão}

Joseph Pilates era reconhecido pelo receio da disseminação de seus exercícios. As notas sobre a técnica foram publicadas somente após seu faleci- 
mento. Desde então, a técnica foi objeto de muitos estudos, que confirmaram seus benefícios e encontraram novas aplicações?.

Curi et al. ${ }^{7}$, ao realizar um estudo com 61 idosas, dividiram as participantes em Grupo Experimental $(\mathrm{GE}=31)$ e Grupo Controle $(\mathrm{GC}=30)$ fizeram o treinamento do mat pilates (pilates no solo) por 16 semanas; verificaram a melhora significativa da percepção de saúde e alguns índices de qualidade de sono em mulheres idosas. Nascimento et al. ${ }^{18}$ também corroboram os benefícios do método na qualidade do sono em idoso. Os pesquisadores realizaram o método pilates por 11 meses, associada à técnica de respiração/relaxamento. Os autores observaram avanços no grau de amplitude articular dos membros superiores, na força da musculatura abdominal, dos glúteos, adutores e abdutores, como também na musculatura dos braços.

De acordo com Queiroz et al. ${ }^{2}$ ao realizarem por 3 meses o pilates solo e a utilização (ou não) de alguns acessórios como, bolas, elásticos e rolo (macarrão), verificaram uma diferença estatisticamente significativa $(\mathrm{p}<0,002)$ entre o valor da média da área muscular do braço, antes $(35,56 \mathrm{~cm} 2)$ e após a prática dos exercícios $(42,72 \mathrm{~cm} 2)$. A melhora da força muscular também foi observada no estudo de Oliveira et al. ${ }^{17}$ onde realizaram um estudo com 30 idosas, sendo 15 idosas no grupo controle que mantiveram suas atividades diárias e 15 idosas no grupo pilates com aparelhos. Verificaram a influência do método pilates na força muscular isocinética dos músculos flexores e extensores do cotovelo, sobre a funcionalidade dos membros superiores por um período de $12 \mathrm{se}$ manas. Na comparação intra-grupo, o grupo que realizou o pilates melhorou a força dos extensores do cotovelo e a funcionalidade dos membros superiores $(\mathrm{p}<0,05)$. Após a intervenção, o grupo que realizou pilates foi superior ao grupo controle em todas as variáveis $(\mathrm{p}<0,05)$, com um grande tamanho de efeito $(\mathrm{d}>0,80)$.

Pestana et al. ${ }^{4}$ também relataram que exercícios baseados em mat pilates após 20 semanas, promoveram uma redução significativa dos níveis séricos de proteína C reativa de alta sensibilidade PCR-hs e medidas antropométricas em idosos.

A prática de exercício físico regular contribui para a prevenção da depressão, independentemen- te da modalidade praticada ${ }^{3}$. Dantas et al. ${ }^{10}$ relataram que os fatores relacionados à saúde, sociabilidade e prazer foram determinantes motivacionais em idosos praticantes do método pilates. Silveira, Lodovici, Bitelli ${ }^{24}$ consideram que o pilates, ioga, dança, excursões, entre outras, são as atividades de maior interesse ou prazer entre os idosos. Aspectos sociais e emocionais também foram avaliados por Duarte, Souza, Nunes ${ }^{21}$, ao verificarem o efeito de um protocolo de intervenção com método pilates e rodas de conversa, concluíram que os idosos melhoraram suas condições emocionais, harmonia corporal, mobilidade global, autonomia funcional e níveis de qualidade de vida, reduzindo o índice de massa corporal.

No estudo de Rodrigues et al. ${ }^{5}$ foram analisados dois grupos. Um grupo que realizou o método Pilates em 27 idosas e o grupo controle, sem o método, em 25 idosas. No primeiro grupo, foi realizado o método usando uma bola Bobath e os aparelhos específicos. A intensidade foi controlada pelo uso das molas do método com constante elástica preestabelecida para todas as participantes. Utilizaram molas de $8,3 \mathrm{kgf} / \mathrm{m}$ para os movimentos de flexão e extensão, abdução e adução de ombros e quadris; de $10 \mathrm{kgf} / \mathrm{m}$ para flexão e extensão de cotovelos e, $29,8 \mathrm{kgf} / \mathrm{m}$ para flexão e extensão de joelhos. A pesquisa teve duração de 08 semanas. Os autores observaram uma melhora significativa do desempenho funcional das idosas que praticaram o método Pilates. Em outro estudo, realizado pelos mesmos autores no ano de 2009, observou-se que o grupo que realizou o método pilates ocorreu uma evolução de 1,03 na pontuação total do teste de Tinetti, já o grupo controle não apresentou uma evolução tão expressiva $(0,32$ pontos) na escala. $\mathrm{Na}$ análise da relação intra-grupo houve uma melhora estaticamente significativa no equilíbrio estático para o grupo que realizou o pilates $(p<0,0001)$, sendo uma ferramenta importante para a redução do risco de quedas, comuns no processo de envelhecimento.

Sendo assim, Souza et al. ${ }^{13}$, avaliaram os efeitos de um programa do método Pilates sobre o equilíbrio de 15 mulheres pós-menopausa iniciantes na modalidade Pilates durante 3 meses e concluíram que as participantes obtiveram no pré-teste uma média de 49,73 pontos com $\pm 3,34$ e no pós-teste obteve uma média de 53,20 pontos e $\pm 2,24$; de- 
monstrando um ganho de $6,9 \%$ no equilíbrio motor $(\mathrm{p}=0,000)$.

Ao investigar e comparar efeito da Facilitação Neuromuscular Proprioceptiva (FNP) e o método Pilates no equilíbrio postural estático e dinâmico em idosas, Mesquita et al. ${ }^{19}$, mostraram que o grupo de FNP obteve um equilíbrio estático e dinâmico significativamente melhor do que as mulheres do grupo controle. As mulheres do grupo Pilates também apresentaram melhor equilíbrio dinâmico do que as mulheres do grupo controle. Porém, não observaram diferenças significativas em qualquer das variáveis de equilíbrio avaliadas entre o grupo de FNP e o grupo Pilates.

Ainda sobre o equilíbrio corporal, Navega et al. ${ }^{23}$ estudaram 31 idosas entre 60 e 75 anos, que foram divididas em dois grupos: grupo controle $(n=17)$ e grupo pilates $(n=14)$. O grupo pilates realizou treinamento, enquanto o grupo controle participou de palestras. A avaliação foi composta por testes específicos de equilíbrio (teste Unipodal direita e esquerda) e de hipercifose torácica (biofotogrametria computadorizada). Ao término das oito semanas ambos os grupos foram reavaliados. O grupo Pilates apresentou manutenção no equilíbrio $(p>0,05)$ e diminuição da hipercifose torácica em média de 6 graus $(\mathrm{p}<0,001)$, enquanto o grupo controle não apresentou diferença significativa ( $p>0,05)$ em nenhuma das variáveis. Os autores concluíram que o método Pilates solo contribuiu na diminuição da hipercifose torácica e na manutenção do equilíbrio das idosas.

Idosos que não praticam nenhum tipo de atividade física orientada de forma regular tendem a ter um menor grau de flexibilidade. O método Pilates induz uma melhora da mobilidade funcional contribuindo para diminuição significativa da limitação motora e prevenção de doenças osteomusculares $^{22}$. Nesse sentido, Tozim et al. ${ }^{6}$, ao realizar um estudo por 08 semanas com um grupo Pilates composto por 14 idosas observaram melhora da flexibilidade no teste sentar e alcançar $(\mathrm{p}=0,033)$, ângulo poplíteo direito $(\mathrm{p}=0,015)$ e esquerdo $(\mathrm{p}=0,0027)$, diminuição do nível de dor ( $\mathrm{p}=0,0187)$ e manutenção da qualidade de vida. Já o grupo controle, composto por 17 idosas que assistiram a palestras não ocorreu diferença significativa.

Pinheiro et al. $^{20}$, analisaram a influência do método Pilates sobre a força e condutibilidade do estímulo elétrico dos músculos paravertebrais lombares, bem como a contração do músculo transverso do abdômen (TrA) em idosas antes e após a realização de exercícios de Pilates no solo. Os instrumentos utilizados foram eletromiógrafo de superfície, transdutor de força e a unidade de Biofeedback Pressórico. Participaram do estudo 13 idosas, que foram submetidas a 12 sessões de exercícios de Pilates no solo com duração média de 50 minutos, sendo reavaliadas no término do protocolo de intervenção. As participantes obtiveram aumento da força e da ativação elétrica dos músculos paravertebrais lombares, bem como aumento na capacidade de contração do músculo transverso do abdômen, sendo o método pilates o treinamento que influenciou positivamente essa musculatura.

Em relação ao princípio que envolve a respiração, Joseph Pilates afirmava que frequentemente respiramos errado por utilizarmos apenas uma fração da capacidade do pulmão. Sendo assim, enfatizava em seu trabalho a respiração como o fator primordial no início do movimento, fornecendo a organização do tronco pelo recrutamento dos músculos estabilizadores profundos da coluna na sustentação pélvica e favorecendo o relaxamento dos músculos inspiratórios e cervicais ${ }^{11}$.

Dentre os sistemas do organismo, acredita-se que o sistema respiratório é o que envelhece mais rapidamente, devido à maior exposição a poluentes ambientais ao longo dos anos. O método Pilates surge como forma de condicionamento físico particularmente interessado em proporcionar bem-estar geral ao indivíduo. Sendo assim, Lopes, Ruas, Patrizzi ${ }^{11}$, avaliaram os efeitos de exercícios do método Pilates na força muscular respiratória de idosas antes e após 11 semanas de treinamento e os resultados mostraram aumento significativo $(\mathrm{p} \leq 0,01)$ em relação à pressão expiratória máxima de $46 \pm 18$ para $75 \pm 29 \mathrm{cmH}_{2} \mathrm{O}$, sendo, o método pilates uma das práticas recomendadas à população idosa. Os autores indicaram que os exercícios devem ser realizados durante a expiração para melhorar a força diafragmática de sujeitos idosos e que não encontraram na literatura trabalhos anteriores que relacionam a prática do método pilates com a força da musculatura respiratória, sugerindo novos estudos.

Quanto à forma de aplicação do método Pilates não há consenso entre os estudos. Dezessete 
estudos descreveram a frequência e duração do tratamento. No entanto, quanto ao tempo das sessões, alguns autores ${ }^{4,5,6,7,13,16,17,18,22,23}$, mencionaram que o tempo da sessão deverá ser de sessenta minutos, mas não houve justificativa sobre essa indicação. Ainda não há uma definição do tempo necessário para alcançar os objetivos propostos pelo tratamento e qual deve ser a frequência de aplicação; sendo que a maioria dos estudos brasileiros recomenda que o método seja aplicado duas vezes por semana. As diferenças apresentadas devem estar relacionadas às características de cada população idosa e às diferentes indicações. Isso ocorre devido à resposta ao exercício que se modifica de acordo com a condição de saúde. Sendo assim, cada disfunção exige um tempo e intensidade diferentes durante o tratamento.

Todos os estudos analisados nesta revisão, mesmo com adaptações, enfatizaram os princípios básicos do método, como: a respiração e a centralização. Os estudos não apresentaram contraindicações; entretanto, chamaram atenção aos cuidados na execução do método e na evolução dos praticantes.

\section{Conclusões}

Diante dos resultados alcançados conclui-se que este estudo demonstra que o Pilates pode ser um método eficaz para o fisioterapeuta na prevenção e tratamento das desordens geriátricas, apresentando vários benefícios e alguns cuidados ao realizá-lo; como os exercícios devem ocorrer de forma progressiva, sempre respeitando os princípios do método e a evolução dos praticantes.

São escassos os estudos com base científica comprovando o efeito do método Pilates em idosos brasileiros, necessitando, portanto, de um maior número de estudos contemplando amostras mais amplas em ambos os sexos; principalmente, incluindo, se possível, idosos do sexo masculino; realização de pesquisas que comparem o método Pilates com outros tipos de exercício físico, bem como estudos que confrontem os exercícios do método no solo com os que utilizam aparelhos e/ ou acessórios.

\section{Referências}

1. Ageing and Life Course. World Health Organization [Internet]. 2016. [acesso em 2018 fev. 3]. Disponível em: http://www.who.int/topics/ageing/em.

2. Queiroz LCS, et al. Efeito da prática do Pilates Solo na massa muscular de mulheres idosas. Rev Rene. 2016 set./ out.; 17(5): 618-25.

3. Ferreira LR, et al. Avaliação dos níveis de depressão em idosos praticantes de diferentes exercícios físicos. Rev ConScientiae Saúde. 2014;13(3):405-410.

4. Pestana MDS et al. Pilates versus resistance exercise on the serum levels of hs-CRP, in the abdominal circumference and body mass index (BMI) in elderly individuals. Rev Motricidade. 2016 jan./mar.; 12(1): 128-140.

5. Rodrigues BGS et al. Autonomia funcional de idosas praticantes de Pilates. Rev Fisioter Pesq. 2010 out./dez.; 17(4): 300-5.

6. Tozim BM et al. Efeito do método Pilates na flexibilidade, qualidade de vida e nível de dor em idosos. Rev ConScientiae Saúde. 2014 dez.; 13(4): 563-570.

7. Curi VS et al. Effects of 16-weeks of Pilates on health perception and sleep quality amongelderly women. Archives of Gerontology and Geriatrics. 2018; 74: 118-122.

8. Silva ACLG, Mannrich G. Pilates na reabilitação: uma revisão sistemática. Rev Fisioter Mov. 2009 jul./set.; 22(3): 449-455.

9. Costa LMR et al. Os Efeitos do Método Pilates Aplicado à População Idosa: Uma Revisão Integrativa. Rev Bras Geriatr Gerontol. 2016 ago.; 19(4): 695-702.

10. Dantas $\mathrm{R}$ et al. Fatores motivacionais de idosos praticantes do método Pilates. Rev Bras Promoç Saúde. 2015 abr./ jun.;28(2): 251-256.

11. Lopes EDS, Ruas G, Patrizzi LJ. Efeitos de exercícios do método Pilates na força muscular respiratória de idosas: um ensaio clínico. Rev Bras Geriatr Gerontol. 2014 set.; 17(3): 517-523.

12. Anderson BD, Spector A. Introduction to Pilates-Based Rehabilitation. Balanced Body. 2005: 1-8.

13. Souza DC et al. Efeitos de um Programa de Pilates sobre o equilíbrio de suas praticantes no período pós-menopausa. Rev Kairós Gerontol. 2013 mar.; 16(2): 39-49.

14. Correa CS et al. Effects of high and low volume of strength training on muscle strength, muscle volume and lipid profile in postmenopausal women. Journal of Exercice Science \& Fitness. 2014; 12: 62-67.

15. Sampaio RF, Mancini MC. Estudos de revisão sistemática: um guia para síntese criteriosa da evidência científica. Rev Bras Fisioter. 2007 jan./fev.; 11(1): 83-89.

16. Rodrigues BGS et al. Avaliação do equilíbrio estático de idosas pós-treinamento com método pilates. Rev Bras $\mathrm{Ci}$ Mov. 2009 jan./mar.; 17(4): 25-33. 
17. Oliveira LC et al. Pilates increases isokinetic muscular strength of the elbow flexor and extensor muscles of older women: a randomized controlled clinical trial. Journal of Bodywork and Movement Therapies. 2017 jan.; 21(1): 2-10.

18. Nascimento MM et al. Programa Interdisciplinar "PAF \& PAPP”: Concepções Metodológicas para a atenção e o cuidado ao idoso e a formação acadêmica. Rev Ciênc \& Saúde Coletiva. 2002; 7(4): 899-906.

19. Mesquita LSA et al. Effects of two exercise protocols on postural balance of elderly women: a randomized controlled trial. BCM Geriatrics. 2015 june.; 2(15): 61.

20. Pinheiro KRG et al. Influence of pilates exercises on soil stabilization in lumbar muscles in older adults. Rev Bras Cineantropom Desempenho Hum. 2014 sept.; 16(6): 648-657.

21. Duarte DS, Sousa CA, Nunes CRO. Effect of Pilates method and conversation circles on the health of older adults. Rev Fisioter Mov. 2017 mar.; 30(1): 39-48.

22. Guimarães ACA et al. The effect of Pilates method on elderly flexibility. Rev Fisioter Mov. 2014 jun.; 27(2): 181188.

23. Navega MT et al. Effect of the Mat Pilates method on postural balance and thoracic hyperkyphosis among elderly women: a randomized controlled trial. Revi Bras Geriatr Gerontol. 2016 june.; 19(3): 465-472.

24. Silveira NDR, Lodovici FMM, Bitelli FSPG. Atividades educacionais participativas e seus efeitos benéficos na vida, pessoal e social, de pessoas idosas - caso da Faculdade da Idade da Razão (FIR/FIG/ UNIMESP). Rev Kairós Gerontol. 2013 set.; 16(3): 325-343. 
Anexos - Tabela 1: Estudos das intervenções do método Pilates em idosos no Brasil:

\begin{tabular}{|c|c|c|c|c|c|c|}
\hline $\begin{array}{l}\text { Autor-ano/ } \\
\text { estado de origem } \\
\text { do trabalho }\end{array}$ & Tipo de estudo & Amostra & Idade & Intervenção & $\begin{array}{c}\text { Frequência/ Intensidade/ } \\
\text { Duração }\end{array}$ & $\begin{array}{c}\text { Principais resultados } \\
\text { encontrados }\end{array}$ \\
\hline $\begin{array}{l}\text { Curi et al.-2018/ } \\
\text { Rio Grande do } \\
\text { Sul. }\end{array}$ & $\begin{array}{l}\text { Ensaio controlado } \\
\text { randomizado. }\end{array}$ & $\begin{array}{l}61 \text { idosas: } \\
\text { GE }(n=31) \\
\text { GC }(n=30)\end{array}$ & $\begin{array}{l}\text { GE: } 64,25 \pm 0,14 \\
\text { anos } \\
\text { GC: } 63,75 \pm 0,08 \\
\text { anos. }\end{array}$ & $\begin{array}{l}\text { GE: Método Pilates Clás- } \\
\text { sico e exercícios de nível } \\
\text { intermediário. } \\
\text { GC: não houve treina- } \\
\text { mento. }\end{array}$ & $\begin{array}{l}60 \text { min., } 2 X \text { por semana, } 1 \\
\text { a } 10 \text { séries com no máximo } \\
10 \text { repetições. Duração } 16 \\
\text { semanas. }\end{array}$ & $\begin{array}{l}\text { Melhora significativa } \\
\text { da percepção de saúde } \\
\text { e alguns índices de } \\
\text { qualidade de sono } \\
\text { em mulheres idosas } \\
\text { do GE, comparado } \\
\text { ao GC. }\end{array}$ \\
\hline $\begin{array}{l}\text { Dantas et al.- } \\
\text { 2015/ Rio de } \\
\text { Janeiro. }\end{array}$ & $\begin{array}{l}\text { Quantitativo, com } \\
\text { delineamento trans- } \\
\text { versal. }\end{array}$ & 39 idosos. & $\begin{array}{l}\text { Igual ou superior } \\
\text { a } 60 \text { anos. }\end{array}$ & Utilizaram o IMPRAF-54. & $\begin{array}{l}\text { Recrutaram os idosos em nove } \\
\text { locais que aceitaram participar } \\
\text { do estudo e permitiram a apli- } \\
\text { cação dos questionários. }\end{array}$ & $\begin{array}{l}\text { Fatores relacionados à } \\
\text { saúde, sociabilidade e } \\
\text { prazer foram deter- } \\
\text { minantes motivacio- } \\
\text { nais entre os idosos } \\
\text { praticantes do MP. }\end{array}$ \\
\hline $\begin{array}{l}\text { Duarte, Souza, } \\
\text { Nunes-2017/ } \\
\text { Santa Catarina. }\end{array}$ & $\begin{array}{l}\text { Delineamento } \\
\text { experimental de caso } \\
\text { único. }\end{array}$ & 24 idosos. & $66 \pm 6$ anos. & $\begin{array}{l}\text { Foram realizados } 10 \\
\text { exercícios com } 4 \text { grupos } \\
\text { de } 6 \text { indivíduos, o MP foi } \\
\text { realizado no solo com e } \\
\text { sem o uso de acessórios: } \\
\text { bola, halteres, peso e outros } \\
\text { dispositivos específicos. }\end{array}$ & $\begin{array}{l}\text { Os idosos alteraram fases com } \\
\text { e sem intervenção, durante } \\
20 \text { semanas, realizadas com } \\
\text { sessões de rodas de conversa } \\
\text { sobre saúde, } 30 \text { min., e de } \\
\text { Pilates, } 45 \text { a } 50 \text { min. Em cada } \\
\text { fase de intervenção foram } \\
\text { realizadas } 10 \text { sessões de } \\
\text { Pilates, } 2 X \text { por semana, de } 5 \text { a } \\
10 \text { repetições. }\end{array}$ & $\begin{array}{l}\text { Melhora através dos } \\
\text { exercícios de Pilates } \\
\text { e círculos de con- } \\
\text { versação binomial; a } \\
\text { autonomia funcional e } \\
\text { níveis de qualidade de } \\
\text { vida; redução o índice } \\
\text { de massa corporal. }\end{array}$ \\
\hline $\begin{array}{l}\text { Ferreira et al.- } \\
\text { 2014/ Rio Grande } \\
\text { do Sul. }\end{array}$ & $\begin{array}{l}\text { Descritivo de corte } \\
\text { transversal. }\end{array}$ & $\begin{array}{l}116 \text { idosos } \\
\text { G1- musculação } \\
(\mathrm{n}=23), \mathrm{G} 2 \text {-hidro- } \\
\text { ginástica }(\mathrm{n}=22), \\
\text { G3-ginástica } \\
\text { aeróbica }(\mathrm{n}=25), \\
\text { G4- Pilates }(\mathrm{n}=22) \text {, } \\
\text { G5-controle }(\mathrm{n}=24) \text {. }\end{array}$ & $\begin{array}{l}\text { Acima de } 60 \\
\text { anos. }\end{array}$ & $\begin{array}{l}\text { Cada voluntário foi entre- } \\
\text { vistado em única sessão, } \\
\text { na qual responderam a } \\
\text { anamnese e ao GDS. }\end{array}$ & $\begin{array}{l}\text { G1 a G4: praticavam regular- } \\
\text { mente a modalidade por um } \\
\text { período superior a } 3 \text { meses, } \\
2 X \text { por semana. } \\
\text { G5: não praticantes de exercí- } \\
\text { cio físico regular. }\end{array}$ & $\begin{array}{l}\text { G1 a G4 apresentaram } \\
\text { valores abaixo da } \\
\text { escala de depressão } \\
\text { (de } 3,86 \pm 1,53 \text { a } \\
6,60 \pm 1,98) .\end{array}$ \\
\hline
\end{tabular}

Fonte: Elaborado pelas autoras, 2018.

Continuação da Tabela 1: Estudos das intervenções do método Pilates em idosos no Brasil:

\begin{tabular}{|c|c|c|c|c|c|c|}
\hline $\begin{array}{l}\text { Autor-ano/ } \\
\text { estado de origem } \\
\text { do trabalho }\end{array}$ & Tipo de estudo & Amostra & Idade & Intervenção & $\begin{array}{c}\text { Frequência/ Intensidade/ } \\
\text { DURAÇão }\end{array}$ & $\begin{array}{c}\text { Principais resultados } \\
\text { encontrados }\end{array}$ \\
\hline $\begin{array}{l}\text { Guimarães et } \\
\text { al.-2014/ Santa } \\
\text { Catarina. }\end{array}$ & $\begin{array}{l}\text { Estudo experimental } \\
\text { controlado. }\end{array}$ & $\begin{array}{l}60 \text { idosos: } \\
\text { GP }(n=30) \\
\text { GC }(n=30)\end{array}$ & $68 \pm 5,1$ anos & $\begin{array}{l}\text { Exercícios do MP com e } \\
\text { sem o uso de aparelhos e } \\
\text { acessórios: Over Ball, The- } \\
\text { ra-Band, Círculo Mágico, } \\
\text { Toning Bola, Rolos, Bola } \\
\text { Suíça, Step Barrel, Barril } \\
\text { de Meia Lua e Caixa para } \\
\text { sentar. }\end{array}$ & $\begin{array}{l}\text { GP: } 60 \text { min., } 2 X \text { por semana, } \\
\text { realizado em pares. Intensida- } \\
\text { de média a moderada, série de } \\
10 \text { a } 12 \text { repetições./ Duração } \\
12 \text { semanas. } \\
\text { GC: não realizaram qualquer } \\
\text { tipo de atividade física. }\end{array}$ & $\begin{array}{l}\text { Na flexibilidade do } \\
\text { quadril o GC não } \\
\text { apresentou diferenças } \\
\text { significativas. No } \\
\text { reteste do GP, este } \\
\text { percentual aumentou } \\
\text { para } 66,7 \% \text {. Em } \\
\text { flexibilidade de ombro } \\
\text { no reteste o número de } \\
\text { idosos aumentou para } \\
33 \% \text { na classificação } \\
\text { superior. }\end{array}$ \\
\hline $\begin{array}{l}\text { Lopes, Ruas, } \\
\text { Patrizzi-2014/ } \\
\text { Minas Gerais. }\end{array}$ & $\begin{array}{l}\text { Ensaio clínico, } \\
\text { longitudinal e pros- } \\
\text { pectivo. }\end{array}$ & 7 mulheres. & $64 \pm 6$ anos. & $\begin{array}{l}\text { Exercícios do MP, cada aula } \\
\text { foi composta por } 5 \text { exercí- } \\
\text { cios e todos os exercícios } \\
\text { foram realizados durante a } \\
\text { expiração, uso de acessó- } \\
\text { rios como o bastão e faixa. }\end{array}$ & $\begin{array}{l}40 \text { min., } 2 \text { X por semana. } \\
\text { Duração: } 11 \text { semanas. }\end{array}$ & $\begin{array}{l}\text { Houve um aumento } \\
\text { significativo ( } \leq \leq 0,01) \\
\text { em relação à PEmáx } \\
\text { de } 46 \pm 18 \text { para } 75 \pm 29 \\
\text { cmH2O. }\end{array}$ \\
\hline $\begin{array}{l}\text { Mesquita et al.- } \\
\text { 2015/ Piauí. }\end{array}$ & $\begin{array}{l}\text { Ensaio controlado } \\
\text { randomizado. }\end{array}$ & $\begin{array}{l}58 \text { mulheres: } \\
\text { GP }(n=20) \\
\text { GFNP }(n=20) \\
\text { GC }(n=18)\end{array}$ & $\begin{array}{l}\text { GP: } 67,3 \pm 4,9 \\
\text { anos. } \\
\text { GFNP: } 68,5 \pm 5,4 \\
\text { anos. } \\
\text { GC: } 71,5 \pm 6,2 \\
\text { anos. }\end{array}$ & $\begin{array}{l}\text { GP: pilates solo, utilizaram } \\
\text { uma Bola Suíça, Thera- } \\
\text {-Band e Círculo Mágico, } \\
\text { formaram grupos com até } \\
\text { três participantes. GFNP: } \\
\text { as sessões foram individu- } \\
\text { alizadas. GC: não houve } \\
\text { intervenção. }\end{array}$ & $\begin{array}{l}\text { GP: } 50 \text { min., } 3 X \text { por semana./ } \\
\text { O número de repetições e re- } \\
\text { sistência aumentaram de nível } \\
\text { ao longo do estudo. GFNP: } \\
50 \text { min., } 3 X \text { por semana, } 1 \text { a } \\
3 \text { séries de } 10 \text { repetições para } \\
\text { cada padrão de diagonal de } \\
\text { movimento. } \\
\text { Duração: } 4 \text { semanas. }\end{array}$ & $\begin{array}{l}\text { O GFNP mostrou um } \\
\text { equilíbrio estático } \\
\text { e dinâmico signifi- } \\
\text { cativamente melhor } \\
\text { do que o GC. O GP } \\
\text { também apresentou } \\
\text { melhor equilíbrio di- } \\
\text { nâmico do que o GC. } \\
\text { Não houve diferenças } \\
\text { significativas entre o } \\
\text { GFNP e GP. }\end{array}$ \\
\hline
\end{tabular}

Fonte: Elaborado pelas autoras, 2018. 
Continuação da Tabela 1: Estudos das intervenções do método Pilates em idosos no Brasil:

\begin{tabular}{|c|c|c|c|c|c|c|}
\hline $\begin{array}{l}\text { Autor-ano/ } \\
\text { estado de origem } \\
\text { do trabalho }\end{array}$ & Tipo de estudo & Amostra & Idade & Intervenção & $\begin{array}{l}\text { Frequência/ Intensidade/ } \\
\text { Duração }\end{array}$ & $\begin{array}{l}\text { Principais resultados } \\
\text { encontrados }\end{array}$ \\
\hline $\begin{array}{l}\text { Nascimento et } \\
\text { al.-2002/ Pernam- } \\
\text { buco. }\end{array}$ & $\begin{array}{l}\text { Projeto de extensão } \\
\text { universitária. }\end{array}$ & 22 mulheres. & $\begin{array}{l}\text { Entre } 60 \text { e } 69 \\
\text { anos. }\end{array}$ & $\begin{array}{l}\text { Exercícios do método Pi- } \\
\text { lates associados a técnicas } \\
\text { de respiração/relaxamento, } \\
\text { postura e percepção corpo- } \\
\text { ral e uso de bola suíça. } \\
\text { Associação a um programa } \\
\text { de palestras de saúde e } \\
\text { atividades criativas. }\end{array}$ & $\begin{array}{l}2 \mathrm{X} \text { por semana, distribuídas } \\
\text { em } 4 \text { fases, de forma grada- } \\
\text { tiva, } 1 \text { série de } 15 \text { exercícios } \\
\text { do método original Pilates/ } \\
\text { Duração } 11 \text { meses. }\end{array}$ & $\begin{array}{l}\text { Avanços no grau de } \\
\text { amplitude articular e } \\
\text { melhora da força mus- } \\
\text { cular dos membros } \\
\text { superiores, abdômen, } \\
\text { glúteos, adutores e } \\
\text { abdutores, qualidade } \\
\text { do sono, realização } \\
\text { das atividades diárias } \\
\text { e equilíbrio dinâmico, } \\
\text { redução de queixas } \\
\text { sobre dor em várias } \\
\text { regiões. }\end{array}$ \\
\hline $\begin{array}{l}\text { Navega et al.- } \\
\text { 2016/ São Paulo. }\end{array}$ & $\begin{array}{l}\text { Estudo randomizado, } \\
\text { longitudinal. }\end{array}$ & $\begin{array}{l}31 \text { mulheres: } \\
\text { GC }(n=17) \\
\text { GP }(n=14)\end{array}$ & $\begin{array}{l}\text { GP: } 67,71 \pm 3,24 \\
\text { anos. } \\
\text { GC: } 65,4 \pm 4,03 \\
\text { anos. }\end{array}$ & $\begin{array}{l}\text { GP: MP no solo, formados } \\
\text { por no máximo } 9 \text { voluntá- } \\
\text { rias, a aplicação ocorreu de } \\
\text { modo progressivo. } \\
\text { GC: } 4 \text { palestras de duração } \\
\text { de } 45 \text { min. }\end{array}$ & $\begin{array}{l}60 \text { min., } 2 X \text { por semana/ de } \\
3 \text { a } 10 \text { exercícios, séries com } \\
2 \text { min. e } 30 \text { s. a } 5 \text { min., e } \\
\text { intervalo de } 1 \text { a } 2 \text { min. } \\
\text { Duração: } 8 \text { semanas. }\end{array}$ & $\begin{array}{l}\text { O GP apresentou ma- } \\
\text { nutenção no equilíbrio } \\
\text { ( }>0,05) \text { e diminuição } \\
\text { da hipercifose torácica } \\
\text { em média de } 6 \text { graus } \\
\text { ( } p<0,001) \text {, enquanto } \\
\text { o GC não apresentou } \\
\text { diferença significativa. }\end{array}$ \\
\hline $\begin{array}{l}\text { Oliveira et al.- } \\
\text { 2017/ Paraná }\end{array}$ & $\begin{array}{l}\text { Ensaio controlado } \\
\text { randomizado. }\end{array}$ & $\begin{array}{l}30 \text { mulheres: } \\
\text { GP }(n=15) \\
\text { GC }(n=15)\end{array}$ & 60 a 70 anos & $\begin{array}{l}\text { Exercícios do MP com uso } \\
\text { de aparelhos. Realizaram } \\
19 \text { exercícios. }\end{array}$ & $\begin{array}{l}\text { GP: } 60 \text { min., } 2 \mathrm{X} \text { por semana. / } \\
\text { Duração: } 12 \text { semanas./ } 1 \text { série } \\
\text { de } 10 \text { repetições/ Nível de } \\
\text { esforço mantido: moderado. } \\
\text { GC: manteve suas atividades } \\
\text { diárias. }\end{array}$ & $\begin{array}{l}\text { Na comparação } \\
\text { intra-grupo, o GP } \\
\text { melhorou a força dos } \\
\text { extensores do cotovelo } \\
\text { e a funcionalidade dos } \\
\text { membros superiores } \\
(\mathrm{p}<0,05) \text {. }\end{array}$ \\
\hline
\end{tabular}

Fonte: Elaborado pelas autoras, 2018.

Continuação da Tabela 1: Estudos das intervenções do método Pilates em idosos no Brasil:

\begin{tabular}{|c|c|c|c|c|c|c|}
\hline $\begin{array}{l}\text { Autor-ano/ } \\
\text { estado de origem } \\
\text { do trabalho }\end{array}$ & Tipo de estudo & Amostra & Idade & Intervenção & $\begin{array}{l}\text { Frequência/ Intensidade/ } \\
\text { Duração }\end{array}$ & $\begin{array}{l}\text { Principais resultados } \\
\text { encontrados }\end{array}$ \\
\hline $\begin{array}{l}\text { Pestana et al.- } \\
\text { 2016/ Bahia. }\end{array}$ & $\begin{array}{l}\text { Ensaio clínico rando- } \\
\text { mizado. }\end{array}$ & $\begin{array}{l}45 \text { idosos: } \\
\text { GP }(n=23) \\
\text { GR }(n=22)\end{array}$ & $\begin{array}{l}\text { Média de } 69 \\
\text { anos de ambos os } \\
\text { sexos. }\end{array}$ & $\begin{array}{l}\text { Programa de exercícios de } \\
\text { resistência: tornozeleiras, } \\
\text { esteiras e cadeiras. Mat } \\
\text { Pilates: bandas elásticas, } \\
\text { esteiras e cadeiras. }\end{array}$ & $\begin{array}{l}60 \text { minutos, } 2 X \text { por sema- } \\
\text { na durante um total de } 20 \\
\text { semanas. } \\
\text { Intensidade moderada. Foram } \\
\text { realizadas } 10 \text { repetições com } \\
\text { intervalo de } 30 \text { segundos entre } \\
\text { as séries. }\end{array}$ & $\begin{array}{l}\text { Exercícios do Mat } \\
\text { Pilates promoveram } \\
\text { uma redução significa- } \\
\text { tiva dos níveis séricos } \\
\text { de PCR-hs e medidas } \\
\text { antropométricas em } \\
\text { idosos. }\end{array}$ \\
\hline $\begin{array}{l}\text { Pinheiro et al.- } \\
\text { 2014/ Piauí. }\end{array}$ & $\begin{array}{l}\text { Estudo descritivo } \\
\text { quantitativo e com- } \\
\text { parativo. }\end{array}$ & 13 mulheres. & $\begin{array}{l}68.63 \pm 6.81 \\
\text { anos. }\end{array}$ & $\begin{array}{l}\text { Pilates solo e acessórios: } \\
\text { Bola Suíça, Thera-Band e } \\
\text { Anel Flex. }\end{array}$ & $\begin{array}{l}50 \text { min., } 3 X \text { por semana./ } \\
\text { As repetições e os exercícios } \\
\text { foram aumentando ao longo } \\
\text { das semanas, } 5 \text { a } 10 \text { repeti- } \\
\text { ções. Duração: } 4 \text { semanas. }\end{array}$ & $\begin{array}{l}\text { Melhora significativa } \\
\text { da força e da condu- } \\
\text { tibilidade elétrica dos } \\
\text { músculos estabiliza- } \\
\text { dores lombares das } \\
\text { voluntárias. }\end{array}$ \\
\hline $\begin{array}{l}\text { Queiroz et al.- } \\
\text { 2016/ Paraná. }\end{array}$ & Quase-experimental & 43 idosas. & $\begin{array}{l}71,23 \pm 6,22 \\
\text { anos. }\end{array}$ & $\begin{array}{l}\text { Pilates solo e a utilização } \\
\text { (ou não) de alguns acessó- } \\
\text { rios, como bolas, elásticos e } \\
\text { rolo (macarrão). }\end{array}$ & $\begin{array}{l}3 \mathrm{X} \text { por semana por } 40 \text { min } \\
\text { cada. Intensidade leve e } \\
\text { moderada, entre } 1 \text { a } 3 \text { séries e } \\
\text { de } 4 \text { a } 10 \text { repetições./ Duração: } \\
3 \text { meses. }\end{array}$ & $\begin{array}{l}\text { Diferença estatistica- } \\
\text { mente significativa } \\
(\mathrm{p}<0,002) \text { entre o } \\
\text { valor da média da área } \\
\text { muscular do braço, an- } \\
\text { tes }(35,56 \mathrm{~cm} 2) \text { e após } \\
\text { a prática dos exercí- } \\
\text { cios }(42,72 \mathrm{~cm} 2) \text {. }\end{array}$ \\
\hline $\begin{array}{l}\text { Rodrigues et al.- } \\
\text { 2009/ Pará. }\end{array}$ & $\begin{array}{l}\text { Quantitativo de } \\
\text { caráter aleatório. }\end{array}$ & $\begin{array}{l}52 \text { idosas. } \\
\text { GP }(n=27) \\
\text { GC }(n=25)\end{array}$ & $66, \pm 4$ anos. & $\begin{array}{l}\text { Exercícios do MP com uso } \\
\text { de aparelhos e Bola Bobath } \\
(55 \mathrm{~cm})\end{array}$ & $\begin{array}{l}\text { GP: } 60 \text { minutos, } 2 X \text { na } \\
\text { semana, a sessão foi composta } \\
\text { por } 10 \text { exercícios com um } \\
\text { máximo de } 10 \text { repetições } \\
\text { cada/ Duração } 8 \text { semanas. GC: } \\
\text { Não sofreu nenhum tipo de } \\
\text { intervenção. Intensidade foi } \\
\text { controlada pelo uso das molas. }\end{array}$ & $\begin{array}{l}\text { Melhora estaticamente } \\
\text { significativa no equilí- } \\
\text { brio estático para o GP } \\
(\mathrm{p}<0,0001) \text {, redução } \\
\text { do risco de quedas. }\end{array}$ \\
\hline
\end{tabular}

Fonte: Elaborado pelas autoras, 2018. 
Continuação da Tabela 1: Estudos das intervenções do método Pilates em idosos no Brasil:

\begin{tabular}{|c|c|c|c|c|c|c|}
\hline $\begin{array}{l}\text { Autor-ano/ } \\
\text { estado de origem } \\
\text { do trabalho }\end{array}$ & Tipo de estudo & Amostra & Idade & Intervenção & $\begin{array}{l}\text { Frequência/ Intensidade/ } \\
\text { Duração }\end{array}$ & $\begin{array}{l}\text { Principais resultados } \\
\text { encontrados }\end{array}$ \\
\hline $\begin{array}{l}\text { Rodrigues et al.- } \\
\text { 2010/ Pará. }\end{array}$ & $\begin{array}{l}\text { Quantitativo de } \\
\text { caráter aleatório. }\end{array}$ & $\begin{array}{l}52 \text { idosas: } \\
\text { GP }(n=27) \\
\text { GC }(n=25)\end{array}$ & $\begin{array}{l}\text { GP: } 66,9 \pm 5,3 \\
\text { anos } \\
\text { GC: } 65,2 \pm 3,9 \\
\text { anos }\end{array}$ & $\begin{array}{l}\text { GP: Prática de Pilates, } \\
\text { usando uma bola Bobath e } \\
\text { os aparelhos específicos do } \\
\text { método. }\end{array}$ & $\begin{array}{l}\text { GP: } 60 \text { minutos, série de } 10 \\
\text { exercícios, máximo de } 10 \\
\text { repetições, } 2 \text { X por semana/ } \\
\text { Duração } 8 \text { semanas. } \\
\text { Intensidade foi controla- } \\
\text { da pelo uso das molas do } \\
\text { método com constante elástica } \\
\text { preestabelecida para todas as } \\
\text { participantes. }\end{array}$ & $\begin{array}{l}\text { Houve melhora sig- } \\
\text { nificativa do desem- } \\
\text { penho funcional das } \\
\text { idosas que praticaram } \\
\text { o MP. }\end{array}$ \\
\hline $\begin{array}{l}\text { Silveira, Lodovi- } \\
\text { ci, Bitelli- 2013/ } \\
\text { São Paulo. }\end{array}$ & $\begin{array}{l}\text { Qualitativo de cará- } \\
\text { ter exploratório. }\end{array}$ & 23 indivíduos & 52 e 84 anos. & $\begin{array}{l}\text { Utilizaram um questionário } \\
\text { aplicado em entrevista em } \\
\text { indivíduos voluntários. }\end{array}$ & $\begin{array}{l}\text { A aplicação do instrumento } \\
\text { metodológico foi individual. }\end{array}$ & $\begin{array}{l}\text { Consideram que o } \\
\text { Pilates, ioga, dança, } \\
\text { excursões entre outras, } \\
\text { são as atividades de } \\
\text { maior interesse ou } \\
\text { prazerosas. }\end{array}$ \\
\hline $\begin{array}{l}\text { Souza et al.-2013/ } \\
\text { Paraná. }\end{array}$ & Pré-experimental. & 15 mulheres. & 58 a 60 anos. & $\begin{array}{l}\text { Exercícios do MP com uso } \\
\text { de aparelhos. }\end{array}$ & $\begin{array}{l}60 \text { minutos, } 2 X \text { na semana. } \\
\text { Intensidade nível básico, } \\
\text { intermediário e avançado. } 10 \\
\text { a } 12 \text { exercícios de } 2 \text { séries } \\
\text { com máximo de } 10 \text { repetições. } \\
\text { Duração } 3 \text { meses. }\end{array}$ & $\begin{array}{l}\text { As idosas obtiveram } \\
\text { um ganho de } 6,9 \% \\
\text { no equilíbrio motor } \\
(\mathrm{p}=0,000) \text {. }\end{array}$ \\
\hline $\begin{array}{l}\text { Tozim et al.-2014/ } \\
\text { São Paulo. }\end{array}$ & $\begin{array}{l}\text { Ensaio controlado } \\
\text { randomizado. }\end{array}$ & $\begin{array}{l}31 \text { idosas: } \\
\text { GP }(n=14) \\
\text { GC }(n=17)\end{array}$ & $65,84 \pm 3,64$ anos. & $\begin{array}{l}\mathrm{GP}=\text { Exercícios do MP no } \\
\text { solo, uso de bola e faixa } \\
\text { elástica. Em grupos com no } \\
\text { máximo } 9 \text { participantes. } \\
\mathrm{GC}=\text { recebeu palestras. }\end{array}$ & $\begin{array}{l}60 \text { min., } 2 \mathrm{X} \text { por semana./ } \\
\text { Intensidade progressiva. } \\
\text { Duração: } 8 \text { semanas. }\end{array}$ & $\begin{array}{l}\text { O GP apresentou } \\
\text { melhora da flexibili- } \\
\text { dade no teste Sentar } \\
\text { e Alcançar, Ângulo } \\
\text { Popliteo, diminuição } \\
\text { do nível de dor e ma- } \\
\text { nutenção da qualidade } \\
\text { de vida. }\end{array}$ \\
\hline
\end{tabular}

Fonte: Elaborado pelas autoras, 2018.

Legenda da tabela 1: GE: grupo experimental, GC: grupo controle, GP: grupo Pilates, n=: número igual (número de indivíduos da amostra), min.: minutos, 2X: duas vezes, MP: método Pilates, IMPRAF-54: Inventário de Motivação à Prática Regular de Atividades Físicas, GDS: Geriatric Depression Scale, PEmáx: pressão expiratória máxima, GFNP: grupo de Facilitação Neuromuscular Proprioceptiva, GR: grupo de resistência, PCR-hs: Proteína C reativa de alta sensibilidade.

Fonte: Elaborado pelas autoras, 2018. 